\title{
Fast Formation of Surface Oxidized Zn Nanorods and Urchin-Like Microclusters
}

\author{
R. López, ${ }^{1}$ T. Díaz, ${ }^{1}$ G. García, ${ }^{1}$ E. Rosendo, ${ }^{1}$ R. Galeazzi, ${ }^{1}$ A. Coyopol, ${ }^{1}$ \\ H. Juárez, ${ }^{1}$ M. Pacio, ${ }^{1}$ F. Morales, ${ }^{1}$ and A. I. Oliva ${ }^{2}$ \\ ${ }^{1}$ Centro de Investigaciones en Dispositivos Semiconductores, Benemérita Universidad Autónoma de Puebla, \\ 14 sur y Avenida San Claudio, Edificio 137, 72570 Puebla, PUE, Mexico \\ ${ }^{2}$ CINVESTAV del IPN Unidad Mérida, Departamento de Física Aplicada, Apartado Postal 73-Cordemex, \\ 97310 Mérida, YUC, Mexico
}

Correspondence should be addressed to R. López; lorr810813@gmail.com

Received 31 May 2013; Accepted 25 November 2013; Published 20 January 2014

Academic Editor: Aloysius Soon

Copyright (C) 2014 R. López et al. This is an open access article distributed under the Creative Commons Attribution License, which permits unrestricted use, distribution, and reproduction in any medium, provided the original work is properly cited.

Entangled $\mathrm{Zn}-\mathrm{ZnO}$ nanorods and urchin-like microstructures were synthesized by the hot filament chemical vapor deposition technique at 825 and $1015^{\circ} \mathrm{C}$, respectively. X-ray diffraction results showed a mixture of $\mathrm{ZnO}$ and $\mathrm{Zn}$ phases in both nanorods and urchin-like structures. The presence of $\mathrm{Zn}$ confirms the chemical dissociation of the $\mathrm{ZnO}$ solid source. The $\mathrm{Z}$ - $\mathrm{ZnO}$ nanorods with diameter of about $100 \mathrm{~nm}$ showed dispersed-like morphology. The urchin-like structures with micrometer diameters exhibited porous and rough morphology with epitaxial formation of nanorods.

\section{Introduction}

Several techniques have been employed in obtaining nanostructured materials due to their potential applications in electronics, optoelectronics, and chemical gas sensing [14]. Recently, micro- and nanoscale composite materials with core-shell structure have stimulated a lot of attention due to their interesting properties such as large surface area and quantum confinement effects. $\mathrm{Zn}-\mathrm{ZnO}$ core-shell structures are of special interest since heterojunctions can be formed at the interface. These structures offer great promise for fabrication of devices as nanotransducers [5], in solar energy conversion [6], and field emission [7], among others. Nowadays several methods are commonly applied to prepare $\mathrm{Zn}-\mathrm{ZnO}$ core-shell structures such as urchin-like [6], nanoparticles [8], and nanorods [9].

Chemical vapor deposition (CVD) and its different experimental configurations such as metal organic CVD, plasma enhanced CVD, laser enhanced CVD, low pressure CVD, and HFCVD have shown versatility and reliability in obtaining a large variety of films, coatings, and recently nanostructures. The HFCVD method requires only a filament and a current source to decompose hydrogen molecules into atomic hydrogen $\left(\mathrm{H}^{*}\right)$. These radicals assist the fast decomposition of several types of gas phase and solid raw materials. In the present work is reported the formation of $\mathrm{Zn}-\mathrm{ZnO}$ nanorods and urchin-like microclusters by the HFCVD technique, using catalytic produced hydrogen atoms as reducing agent.

\section{Materials and Methods}

$\mathrm{Zn}-\mathrm{ZnO}$ nanorods and urchin-like microclusters were fabricated by the HFCVD technique by using $\mathrm{ZnO}$ powders as reactant material. Although the main characteristic of the HFCVD system is that it uses a metallic filament, it is known that by contact with $\mathrm{SiH}_{4}$ or $\mathrm{H}_{2}$ it yields hydrogen atoms when it is heated at $1600^{\circ} \mathrm{C}$ and above $[10,11]$. The aim of using hydrogen atoms was to produce $\mathrm{Zn}$ and $\mathrm{OH}$ gases from a $\mathrm{ZnO}$ solid source in a short period of time in relation to other methods. Actually, the amount of hydrogen atoms in HFCVD is in some cases by one or two orders larger than in PECVD system [12]. Since the hydrogen atoms concentration 
depends upon the distance from the filament [13], the $\mathrm{ZnO}$ solid source was placed around $2 \mathrm{~mm}$ under the filament. $\mathrm{ZnO}$ powders were compressed in order to obtain a tablet of $0.2 \mathrm{~g}$. The $\mathrm{ZnO}$ tablet with cylindrical shape was loaded into the center of a quartz tube (diameter $60 \mathrm{~mm}$, length $350 \mathrm{~mm}$ ) and under of a tungsten filament. The filament has a parallel array to minimize thermal gradients between individual wires and offer uniform heating over the substrate. The substrates were placed 6 and $4 \mathrm{~mm}$ on each experiment below the filament during five minutes, reaching substrate temperatures of 825 and $1015^{\circ} \mathrm{C}$ (Figure 1), respectively. Ptype (100) oriented silicon wafers and resistivity $\rho=1-3 \Omega *$ $\mathrm{cm}$ were used as substrates. By applying an AC voltage of $83.4 \mathrm{~V}$ the filament was heated up to $2000^{\circ} \mathrm{C}$. The vapor precursor production and the substrate chemical reactions are proposed as follows:

$$
\begin{gathered}
\mathrm{ZnO}(\mathrm{s})+2 \mathrm{H}^{*}(\mathrm{~g}) \longrightarrow \mathrm{Zn}(\mathrm{g})+\mathrm{H}_{2} \mathrm{O}(\mathrm{g}) \\
\mathrm{ZnO}(\mathrm{s})+\mathrm{H}_{2}(\mathrm{~g}) \longrightarrow \mathrm{Zn}(\mathrm{g})+\mathrm{H}_{2} \mathrm{O}(\mathrm{g}) \\
\mathrm{Zn}(\mathrm{g})+\mathrm{H}_{2} \mathrm{O}(\mathrm{g}) \longrightarrow \mathrm{ZnO}(\mathrm{s})+\mathrm{H}_{2}(\mathrm{~g})
\end{gathered}
$$

Reaction (1) is produced on the $\mathrm{ZnO}$ tablet and reaction (2), onto the substrate surface. The XRD diffractograms were measured with a Bruker D8 Discover diffractometer using Cu $\mathrm{K} \alpha$ radiation (1.5418 $\AA$ ). The morphology of the products was characterized by using a scanning electron microscopy (SEM) Phillips XL-30.

\section{Results}

Figure 2 shows XRD spectra measured from samples deposited at 825 and $1015^{\circ} \mathrm{C}$. The analysis of each diffractogram shows that there is a mixture of $\mathrm{ZnO}$ and $\mathrm{Zn}$ phases in both samples. However, it seems that $\mathrm{ZnO}$ exhibits better crystallization characteristics than $\mathrm{Zn}$ since it shows stronger and sharper diffraction lines, including the overlapping $\mathrm{Zn}$ (002) and $\mathrm{ZnO}$ (101) peaks. The formation of $\mathrm{Zn}$ traces can be ascribed to the condensation of $\mathrm{Zn}$ vapor, which may confirm the reduction of the $\mathrm{ZnO}$ tablet by hydrogen atoms and molecules, as was suggested in (1). Several authors have reported a better crystallization of $\mathrm{ZnO}$ by increasing the growth temperature [14-16]. This has been attributed to increase of surface mobility of $\mathrm{Zn}$ and oxygen atoms in higher temperatures. However, these results were obtained in substrate temperatures lower than $600^{\circ} \mathrm{C}$.

The morphology of the products obtained by the HFCVD technique at 825 and $1015^{\circ} \mathrm{C}$ is shown in Figures 3 and 4 . Different morphologies can be clearly seen by changing the growth temperature from 825 to $1015^{\circ} \mathrm{C}$. In Figure 3(a), the product deposited at $825^{\circ} \mathrm{C}$ exhibits a porous and nonuniform structure. Figure 3(b) shows a high magnification SEM image of this sample. A large quantity of nanoscale rodlike structures can be seen. The diameter of the nanorods is observed to be relatively uniform (100 $\mathrm{nm}$ approximately) and their lengths of several micrometers. The nanorods are not aligned and have a scattered distribution. From XRD spectra, we suggest that they are $\mathrm{Zn}-\mathrm{ZnO}$ structures. The formation of the $\mathrm{Zn}-\mathrm{ZnO}$ nanorods can be explained by

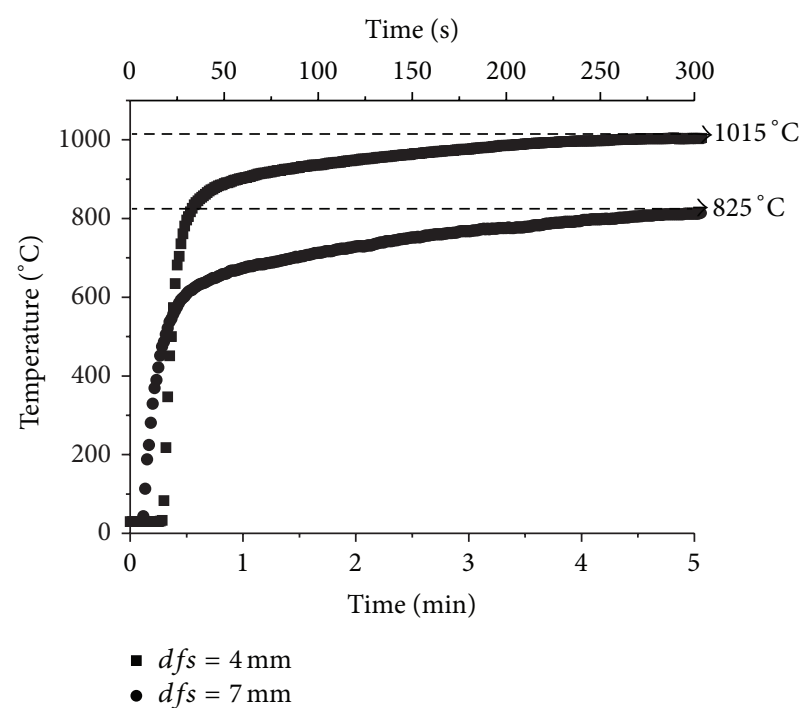

FIGURE 1: Heating rate and deposit temperature of $\mathrm{ZnO}$ nanorods and microclusters grown by the HFCVD technique.

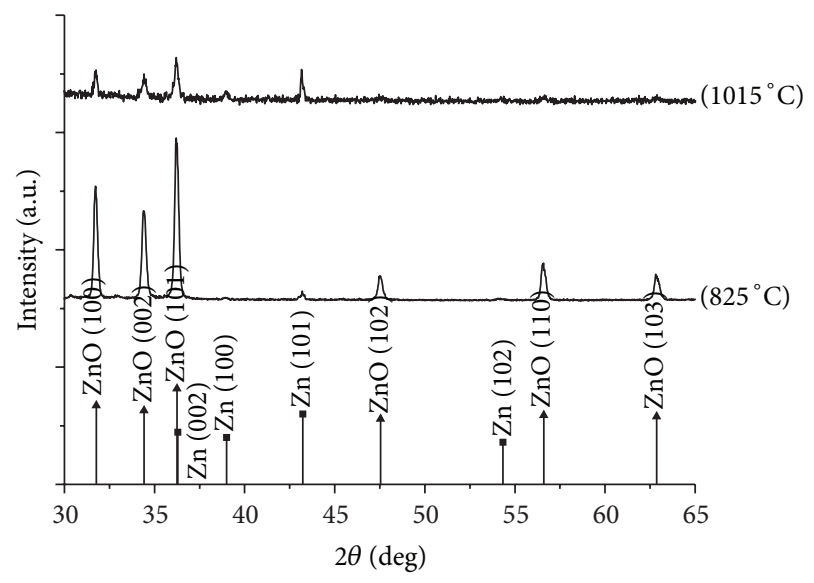

FIgURE 2: XRD spectra of the $\mathrm{Zn}-\mathrm{ZnO}$ nanorods and microclusters deposited at 825 and $1015^{\circ} \mathrm{C}$, respectively.

the vapor-liquid-solid (VLS) mechanism. Zn vapor is quickly produced by reaction between atomic hydrogen and the $\mathrm{ZnO}$ solid source. Then, $\mathrm{Zn}$ vapor diffuses towards lower temperature region (substrate surface). The $\mathrm{Zn}$ species condensate and then nucleate at short time forming $\mathrm{Zn}$ nanodroplets. The surface of the nanodroplets provides many sites for adsorption and hence $\mathrm{Zn}$ atoms easily grow onto these liquid structures forming $\mathrm{Zn}$ nanorods. The water vapor produced by reduction of the $\mathrm{ZnO}$ solid source (1) oxidizes the surface of the $\mathrm{Zn}$ nanorods. Figure 4(a) is a low magnification SEM image of the sample deposited at $1015^{\circ} \mathrm{C}$ which shows that the substrate is covered with irregular shaped microclusters. It is observed that a great number of these clusters coalesced forming bigger structures. Also, some of them have partly opened mouth. Figure 4(b) is a SEM image of a single microcluster with diameter around 50 micrometers. A hollow 


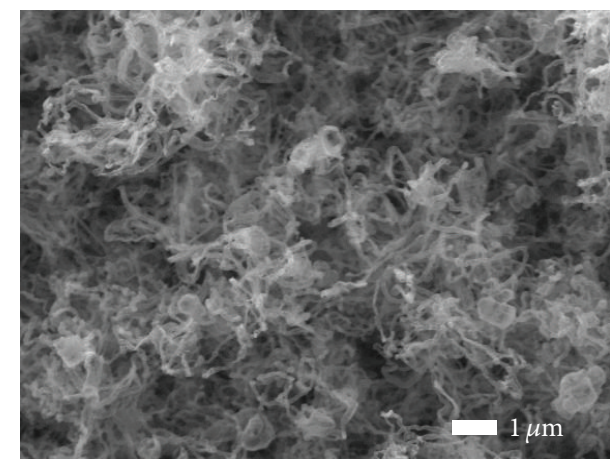

(a)

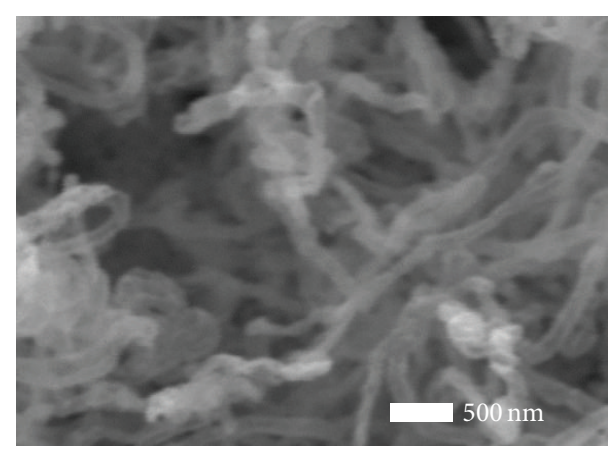

(b)

FIGURE 3: SEM images of ZnO nanorods: (a) low magnification image and (b) high magnification image. ZnO nanorods with diameters around $100 \mathrm{~nm}$ can be observed.

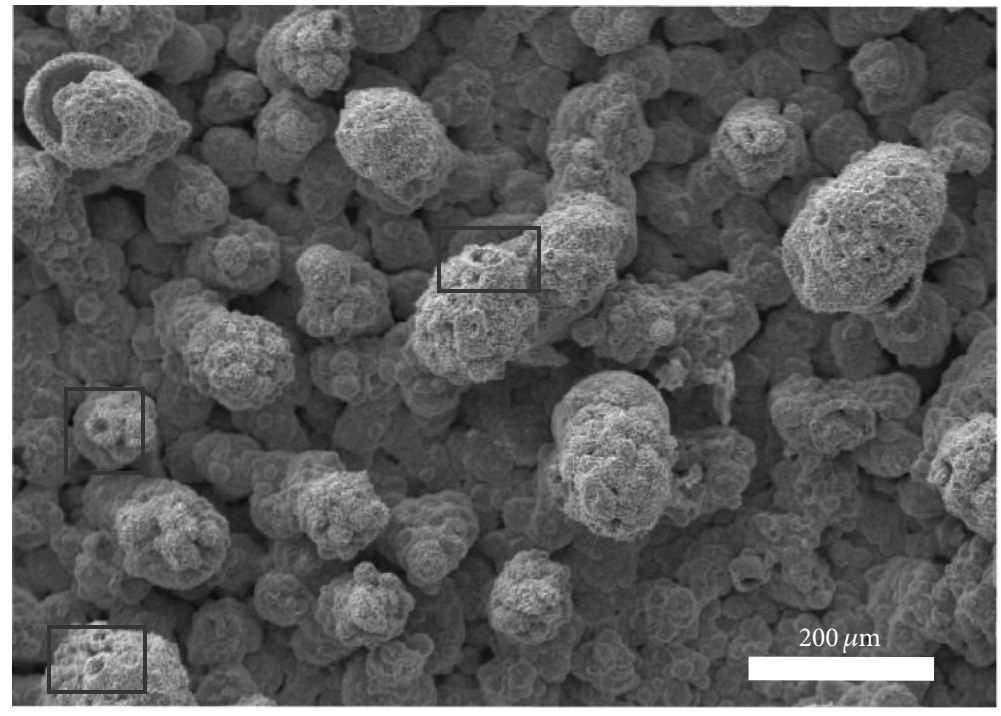

(a)

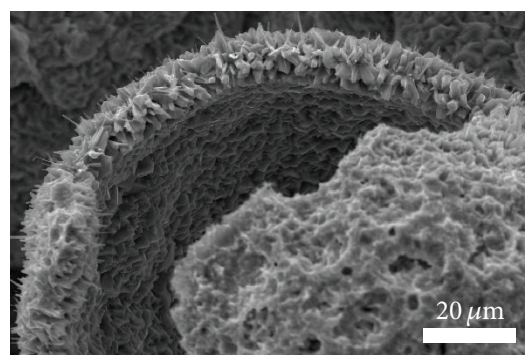

(c)

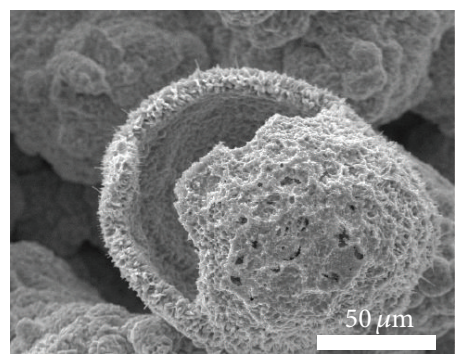

(b)

FIGURE 4: SEM images of ZnO microclusters: (a) low magnification, (b) individual ZnO microcluster, and (c) high magnification of the $\mathrm{ZnO}$ microcluster.

core is observed on this cluster. The surface of it is rough and porous and in some areas the presence of a lot of small rodlike nanostructures is observed (Figure 4(c)).

The proposed growth mechanism of the microclusters obtained at $1015^{\circ} \mathrm{C}$ is proposed as follows: the generated $\mathrm{Zn}$ gas diffuses toward the substrate surface where it nucleates forming many small nanodroplets. Some of these droplets may coalesce at $1015^{\circ} \mathrm{C}$ producing bigger structures than those formed at $825^{\circ} \mathrm{C}$. The surface of the $\mathrm{Zn}$ droplets quickly oxidizes, resulting in core-shell $\mathrm{Zn}-\mathrm{ZnO}$ clusters. In some cases the interior of the clusters overpressures and cracks the outer shell and leaves the $\mathrm{Zn}$ vapor from the droplet. Thus, the solid $\mathrm{Zn}$ spheres transform into $\mathrm{ZnO}$ hollow microclusters. The reevaporated $\mathrm{Zn}$ vapor condensates and oxidizes, forming epitaxial $\mathrm{ZnO}$ nanorods on the surface of the $\mathrm{ZnO}$ hollow microclusters. 


\section{Conclusions}

In summary, the HFCVD technique has been employed to fabricate $\mathrm{Zn}-\mathrm{ZnO}$ nanorods and microclusters by using a $\mathrm{ZnO}$ tablet as solid source and hydrogen molecules and atoms as reducing species. XRD spectra showed a mixture of $\mathrm{Zn}$ and $\mathrm{ZnO}$ phases. However, $\mathrm{ZnO}$ showed better crystallization characteristics than $\mathrm{Zn}$. On the other hand, it was suggested that the formation of the $\mathrm{Zn}-\mathrm{ZnO}$ nanorods and microclusters follows a VLS mechanism, which starts from condensed Zn nanodroplets.

\section{Conflict of Interests}

The authors declare that there is no conflict of interests regarding the publication of this paper.

\section{Acknowledgments}

The authors thank CONACYT México and VIEP BUAP for the financial support.

\section{References}

[1] H. Kind, H. Yan, M. Law, B. Messer, and P. Yang, "Nanowire ultraviolet photodetectors and optical switches," Advanced Materials, vol. 14, no. 2, pp. 158-160, 2002.

[2] B. P. Zhang, N. T. Binh, Y. Segawa, K. Wakatsuki, and N. Usami, "Optical properties of $\mathrm{ZnO}$ rods formed by metalorganic chemical vapor deposition," Applied Physics Letters, vol. 83, no. 8, pp. 1635-1637, 2003.

[3] G. Du, Y. Ma, Y. Zhang, and T. Yang, "Preparation of intrinsic and $\mathrm{N}$-doped $p$-type $\mathrm{ZnO}$ thin films by metalorganic vapor phase epitaxy," Applied Physics Letters, vol. 87, pp. 213103-213105, 2005.

[4] D. C. Kim, B. H. Kong, and H. K. Cho, "Morphology control of $1 \mathrm{D} \mathrm{ZnO}$ nanostructures grown by metal-organic chemical vapor deposition," Journal of Materials Science, vol. 19, no. 8-9, pp. 760-763, 2008.

[5] X. Y. Zhang, J. Y. Dai, C. H. Lam et al., "Zinc/ZnO core-shell hexagonal nanodisk dendrites and their photoluminescence," Acta Materialia, vol. 55, no. 15, pp. 5039-5044, 2007.

[6] D.-M. Tang, G. Liu, F. Li et al., "Synthesis and photoelectrochemical property of urchin-like $\mathrm{Zn} / \mathrm{ZnO}$ core-shell structures," Journal of Physical Chemistry C, vol. 113, no. 25, pp. 11035-11040, 2009.

[7] C. Y. Kuan, M. H. Hon, J. M. Chou, and I. C. Leu, "Growth behavior, microstructure characterization, and field-emission property of 6-fold hierarchical $\mathrm{Zn} / \mathrm{ZnO}$ structures prepared by direct annealing," Crystal Growth \& Design, vol. 9, no. 2, pp. 813819, 2007.

[8] S. C. Singh, R. K. Swarnkar, and R. Gopal, "Zn/ZnO core/shell nanoparticles synthesized by laser ablation in aqueous environment: optical and structural characterizations," Bulletin of Materials Science, vol. 33, no. 1, pp. 21-26, 2010.

[9] M. Trejo, P. Santiago, H. Sobral, L. Rendón, and U. Pal, "Synthesis and growth mechanism of one-dimensional $\mathrm{Zn} / \mathrm{ZnO}$ core-shell nanostructures in low-temperature hydrothermal process," Crystal Growth and Design, vol. 9, no. 7, pp. 3024-3030, 2009.
[10] H. Wiesmann, A. K. Ghosh, T. McMahon, and M. Strongin, “a$\mathrm{Si}$ : H produced by high-temperature thermal decomposition of silane," Journal of Applied Physics, vol. 50, no. 5, pp. 3752-3754, 1979.

[11] A. Masuda, K. Imamori, and H. Matsumura, "Influence of atomic hydrogen on transparent conducting oxides during hydrogenated amorphous and microcrystalline Si preparation by catalytic chemical vapor deposition," Thin Solid Films, vol. 411, no. 1, pp. 166-170, 2002.

[12] J. Wei, J. M. Chang, and Y. Tzeng, "Deposition of diamond films with controlled nucleation and growth using hot filament CVD," Thin Solid Films, vol. 212, no. 1-2, pp. 91-95, 1992.

[13] H. Umemoto, K. Ohara, D. Morita, Y. Nozaki, A. Masuda, and H. Matsumura, "Direct detection of $\mathrm{H}$ atoms in the catalytic chemical vapor deposition of the $\mathrm{SiH}_{4} / \mathrm{H}_{2}$ system," Journal of Applied Physics, vol. 91, no. 3, pp. 1650-1656, 2002.

[14] S. Cho, "Effects of growth temperature on the properties of $\mathrm{ZnO}$ thin films grown by radio-frequency magnetron sputtering," Transactions on Electrical and Electronic Materials, vol. 10, no. 6, pp. 185-188, 2009.

[15] F. K. Shan and Y. S. Yu, "Optical properties of pure and Al doped $\mathrm{ZnO}$ thin films fabricated with plasma produced by excimer laser," Thin Solid Films, vol. 435, no. 1-2, pp. 174-178, 2003.

[16] J. D. Ye, S. L. Gu, S. M. Zhu et al., "Substrate temperature dependence of properties of $\mathrm{ZnO}$ thin films deposited by LPMOCVD," Applied Physics A, vol. 78, no. 5, pp. 761-764, 2004. 

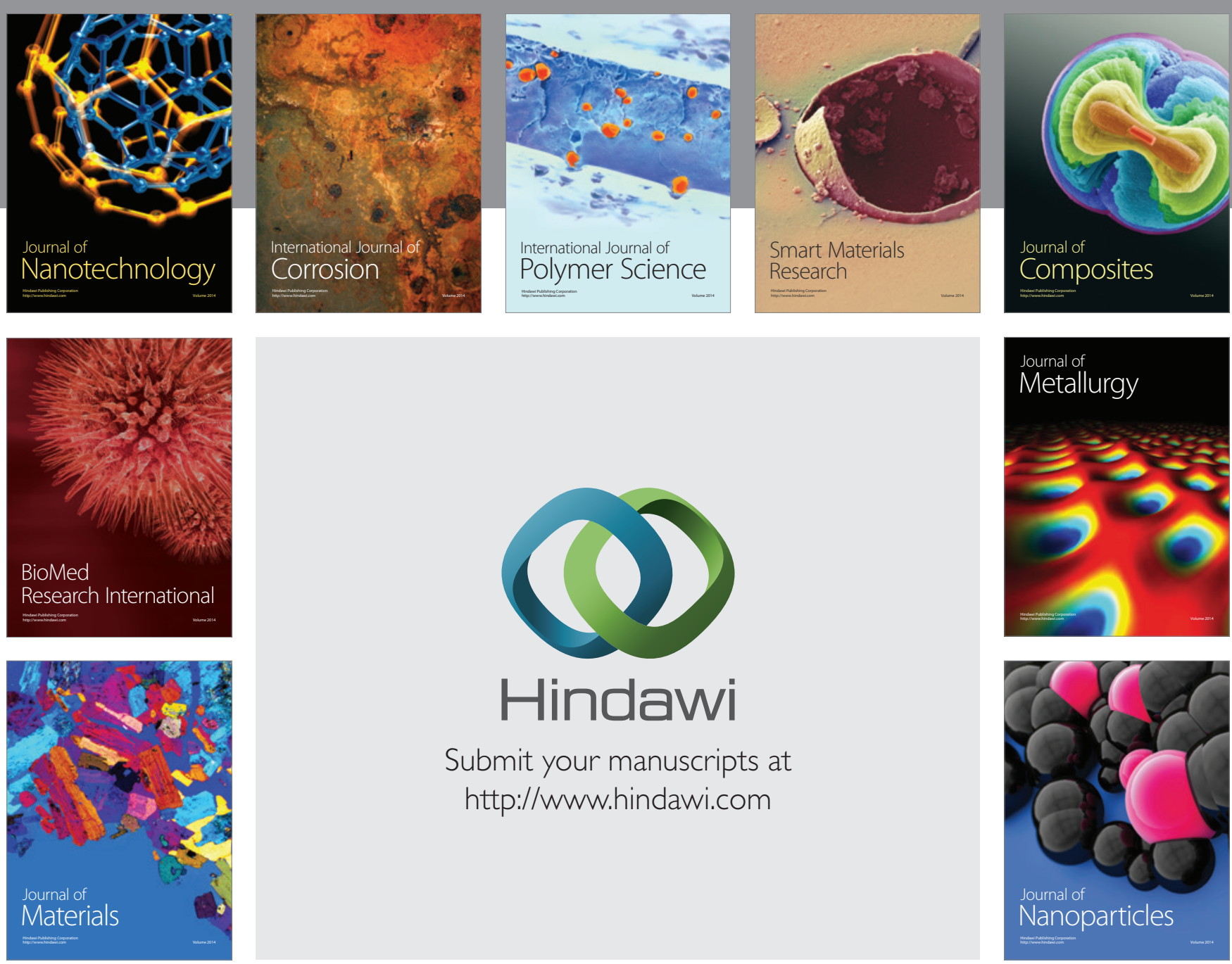

Submit your manuscripts at http://www.hindawi.com
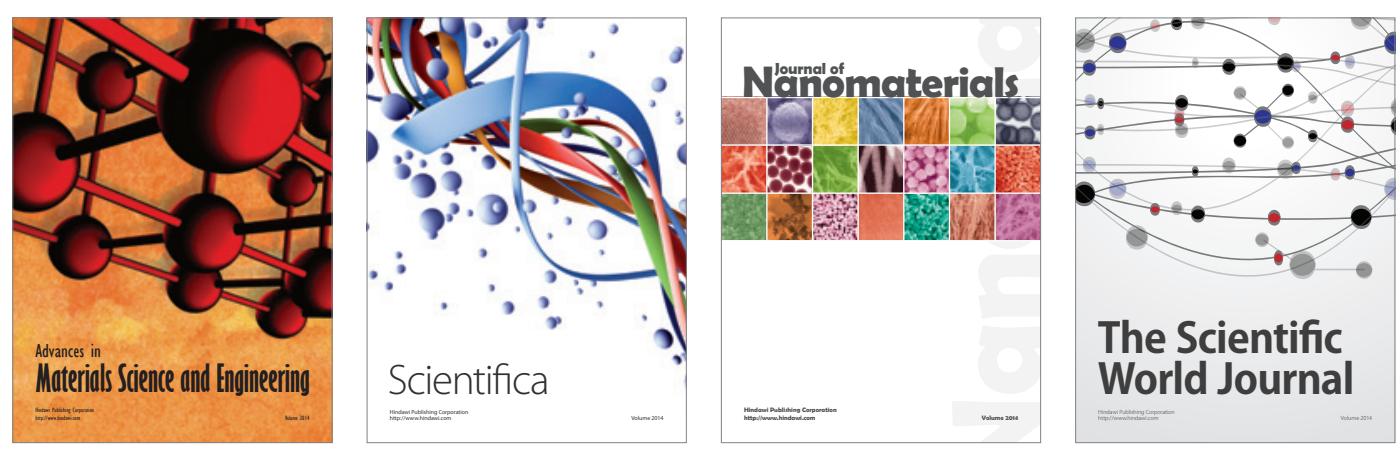

\section{The Scientific World Journal}
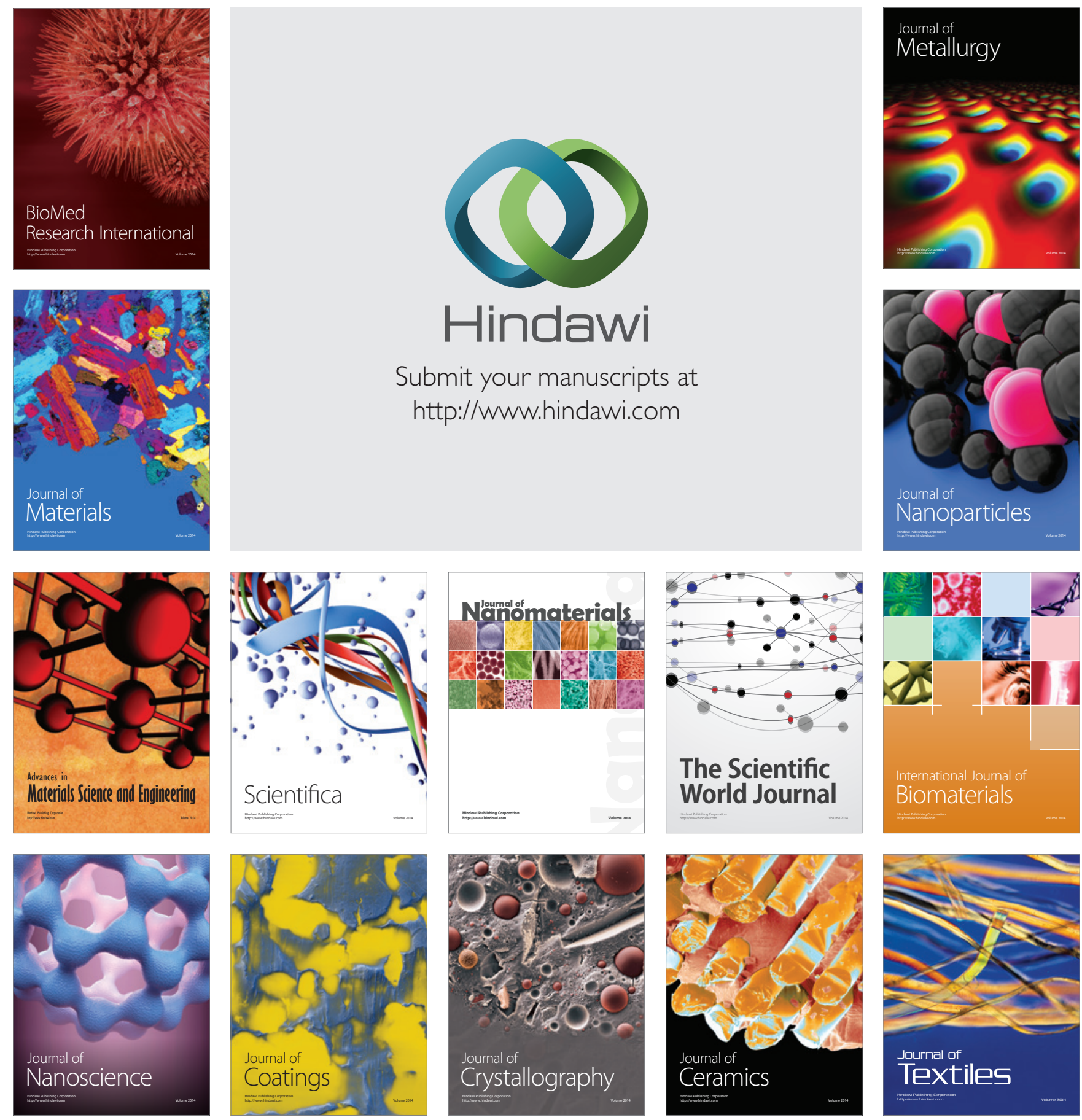